\title{
Causes of destruction of continuous welded rail tracks
}

\author{
Svetlana Gertsyk and Natalya Volgina*
}

The Moscow polytechnical university, B. Semenovskaya St., 38, Moscow, 107023, Russia

\begin{abstract}
The main causes of destruction of continuous welded rail tracks, the main types of their destruction and the causes of their occurrence are considered. The technologies for the manufacture of rails are analyzed, including heat treatment along the entire length of the rail, treatment of the ends of the rail, surface hardening and anti-flake treatment. To increase the durability of rail tracks, a number of measures have been proposed.
\end{abstract}

An increase in the total volume of freight traffic by rail calls for upgrades of the operational characteristics of railways and for reduction of the cost of its manufacture. Therefore, most of the rail tracks are continuous tracks, i.e. a welded whip with a length of 800 meters and more, made of rails of standard dimensions with a length of $25 \mathrm{~m} \mathrm{[1].}$

Three main types of rail welded joints used in Russia are aluminum-thermite (Fig.1), manual arc and resistance butt welding, of which the contact welding method is most often used.

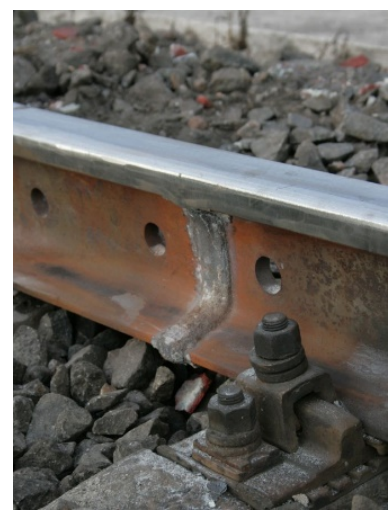

Fig. 1. Welded joint obtained by the aluminum-thermite method

Rails are the main element of the railway track. The established limit norms for static load on the axles of locomotives are $225-245 \mathrm{kN}$, on the axles of cars - up to 220, their speed can exceed $100 \mathrm{~km} / \mathrm{h}$. These indicators, as well as high freight traffic, growing travel speeds and train mass determine conditions for the safe operation of rails. When rolling stock moves, rails might experience alternating bending stresses, reaching up to $240 \mathrm{MPa}$, high specific

* Corresponding author: nvolgina2008@gmail.com 
contact pressures up to $240 \mathrm{MPa}$; shock loads during wheel rolling are possible on the butt sections of the rails. The amount of wheel slip on curved track sections can be 2-3\% [2].

Railway transport belongs to the category of hazardous, so various rail defects and damages arising during its operation are classified by JSC «VNIIZhT» (Jont Stock Company «Ralway Reasearch Institute») into nine groups in correspondence with main elements of the rail (Fig. 2) [3, 4].

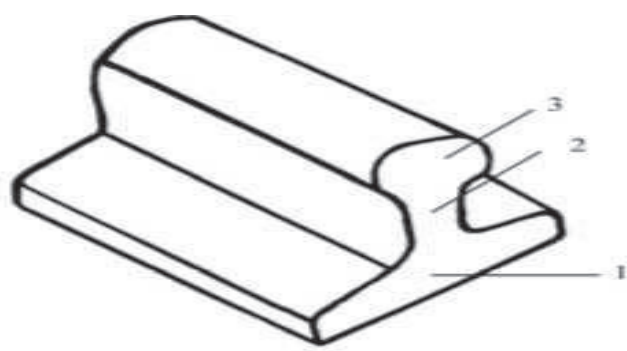

Fig. 2. Elements of a railway rail: 1 - base; 2 - neck; 3 - head

Rail defects include: transverse defects, subdivided into transverse, complex and surface cracks; breaks from the boxes; horizontal and vertical head stratification; shrinkage cavities in the "body" of the rail; rails with a knocked-down head; stratification of the neck; fractures of the sole; fresh transverse fractures. The most dangerous are transverse defects, which can cause sudden transverse fracture of the rails. Damaged rails, according to the degree of danger of defects, are subdivided into acutely defective destroyed (ADD), which can lead to sudden destruction and defective and (DD) acutely.

The most reliable method of detecting rail defects is flaw detection - one of the main methods of non-destructive testing, which allows to detect internal defects and structural inhomogeneity of the rail body (cracks, non-metallic inclusions, etc.). Magnetic (Fig. 3) and ultrasonic (Fig. 4) flaw detection methods are commonly used for the flaw detection of the rails $[5,6]$.

A magnetic rail flaw detector (MRD-66) usually detects defects in the rail head: fractures without visible flaws, cracks from slipping, fatigue cracks in the form of light and dark spots, under the rolling surface of the rail head at a depth of no more than $4 \mathrm{~mm}$.
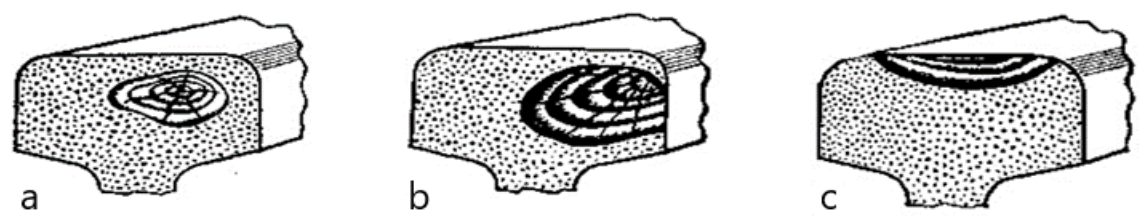

Fig. 3. Defects in rails detected by magnetic flaw detectors: a - internal tear; b - internal crack; c hardening crack in the rail head

The most common reasons for the formation of cracks and fractures are the presence of internal tears due to flakes, gas bubbles and other defects (Fig.3a), internal tears caused by insufficient contactfatigue strength of the metal (Fig.3b), and formation of hardening cracks (Fig.3c) [7].

Ultrasonic flaw detectors allow to detect metal delamination caused by violation of rail manufacturing technology (Fig. 4a), longitudinal cracks under the rail head due to poor-quality rolling (Fig.4b), and cracks in the area of the first bolt hole under the rail fasteners (Fig.4c). 

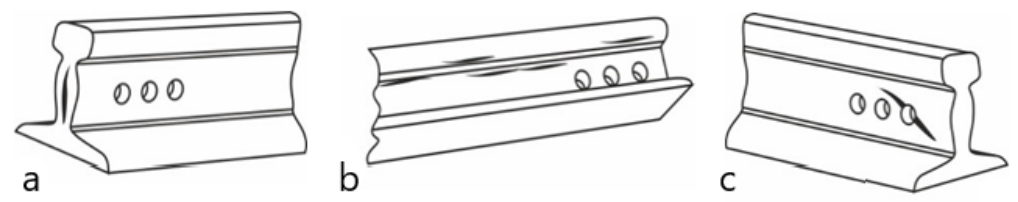

Fig. 4. Defects in rails detected by ultrasonic flaw detectors: a - metal delamination: $\mathrm{b}$ - longitudinal crack under the head; c - cracks in the area of the first bolt hole

The most common types of rail head wear are delamination and chipping of metal along the rolling surface, longitudinal and transverse cracks leading to fracture, wrinkling and uneven wear of the head itself. JSC VNIIZhT classification also includes defects and damage to the rail neck and foot, as well as fractures and bends of the rails.

At first the service life of a rail was increased by making it heavier and by increasing the carbon content of the rail steel (Table 1). At present, a number of technological measures are actively used for this purpose, including reduction of the metallurgical contamination of the steel melt, microalloying the melt to increase the strength of rail steel, and mandatory heat treatment of the finished product. One more way to improve the strength characteristics is to improve the rail profile. The most effective measure is the thermal rail hardening over its entire length, which makes it possible to increase its operational reliability and durability by 1.5 times [4-6].

Table 1. Chemical composition of rail steels, \% (GOST 24182-80)

\begin{tabular}{|l|l|l|l|l|l|l|l|}
\hline $\begin{array}{l}\text { Rail } \\
\text { type }\end{array}$ & $\begin{array}{l}\text { Brand } \\
\text { steel }\end{array}$ & $\mathrm{C}$ & $\mathrm{Mg}$ & $\mathrm{Si}$ & $\mathrm{P}$ & $\mathrm{S}$ & $\mathrm{Al}$ \\
\hline $\begin{array}{l}\text { P75, } \\
\text { P65 }\end{array}$ & $\mathrm{M} 76$ & $0,71-0,82$ & $0,75-1,05$ & $0,18-0,40$ & $\leq 0,035$ & $\leq 0,045$ & $\leq 0,15$ \\
\hline P50 & M74 & $0,69-0,80$ & $0,75-1,05$ & $0,18-0,40$ & $\leq 0,035$ & $\leq 0,045$ & $\leq 0,15$ \\
\hline
\end{tabular}

In the hot-rolled state, the grain size in rail steel corresponds to 2-3 points (according to GOST 5639-82), after heat treatment with phase recrystallization - 7-8 points. The structure of steel in the hot-rolled state is a sorbitol-like pearlite with thin inclusions of ferrite. The hardenability is $4-6 \mathrm{~mm}$ when determined by the end hardening method (GOST 5657-69) [5]. The scheme of the technological process of rail production usually provides an opportunity for three types of heat treatment: anti-flake heat treatment; thermal hardening of the ends of the rail; thermal hardening along the entire length of the rail.

Rail heat treatment technology. After casting and rolling, rail steel usually contains 5-9 $\mathrm{cm}^{3}$ of hydrogen per $100 \mathrm{~g}$ of metal and is flake-sensitive, as a result of decrease in solubility of atomic hydrogen in $\alpha$-iron during the $\mathrm{Fe} \gamma \rightarrow \mathrm{Fe} \alpha$ phase transition and its release into microvoids with the formation of flocs causing the formation of small transverse fatigue cracks, which during operation can lead to the complete destruction of the rail.

In rail rolling shops, heat treatment of rail packages is used either by slow cooling from the temperature of rolling heating or by isothermal holding in furnaces. Both processes reduce the hydrogen content in the melt to $\sim 2.0 \mathrm{~cm} 3 / 100 \mathrm{~g}$ of metal, which practically guarantees the absence of flocs in the rail body. Both types of heat treatment are carried out after the completion of the $\mathrm{Fe} \gamma \rightarrow \mathrm{Fe} \alpha$ transformation, accompanied by a sharp decrease in the solubility of hydrogen in the metal. Heat treatment parameters (temperature, heating rate, holding time and slow cooling rate, as well as the design of the units used) are determined by the size of the load, by the weight and the size of the package of the processed rails.

Hardening of the ends of rails is carried out at all factories that produce rails, since the ends perceive the greatest dynamic load from the wheels of the rolling stock, which is why they quickly crumple, crumble and collapse as a result of the formation of operational defects 
(of course, this method of strengthening is used for rails that are not heat treated along their entire length).

According to the current standards for rails (GOST 51685-2013), the hardening of the ends of the railheads is provided for the length of at least $80 \mathrm{~mm}$, with the depth of the hardened layer of at least $4 \mathrm{~mm}$ with the obtained hardness $\mathrm{HB} \geq 300$. The structure of the hardened layer should gradually blend with the structure of the core both in the transverse cross-section and on the rolling surface.

Strengthening of the ends of the rail by surface hardening with cooling in water can be done in two ways: from rolling or induction heating. Hardness after hardening - HB 330-400. The advantage of this treatment is the low cost of the process, and the disadvantage is poorly controlled temperature in the hardening cycle, which does not allow to obtain stable properties of the hardened layer.

The microstructure of the hardened layer is tempered sorbitol, which turns into a narrow band of bainite 3-4 mm deep and then into hardened sorbitol with scattered small inclusions of ferrite. This structural inhomogeneity is associated with a high cooling rate during quenching and often leads to the formation of chips during operation of rails [6-8].

The mechanical properties of a rail after such processing (in accordance with the requirements of standards) should be as follows: tensile strength $\sigma_{\mathrm{B}} \geq 1170 \mathrm{MPa}$, yield strength $\sigma_{\mathrm{T}} \geq 750 \mathrm{MPa}$, relative expansion $\delta \leq 6 \%$, relative narrowing $\psi \leq 20 \%$, impact strength $\mathrm{KCU} \geq 0.25 \mathrm{MJ} / \mathrm{m}^{2}$, work of destruction at $60{ }^{\circ} \mathrm{C} \mathrm{K} \geq 4.2 \mathrm{~kJ}$.

For the full-length rail heat treatment volumetric quenching with cooling in oil and surface hardening from induction heating are used. Cooling in oil leads to the transformation of supercooled austenite in the pearlite region with the formation of thin-plate hardened sorbitol over the entire section of the rai [9]1.

The volumetric thermal hardening with oil quenching of a 25 -meter rail increases its length by an average of $18 \mathrm{~mm}$, and straightening shortens it by about $20 \mathrm{~mm}$ [1]. Changing the length during heat treatment and straightening is the main disadvantage of this type of rail hardening technology (oil quenching), since it often brings the length dimension beyond the allowed tolerance of $\pm 6 \mathrm{~mm}$.

\section{Conclusions}

The main advantage of the technology of volumetric quenching with cooling in oil and subsequent tempering is the provision of high mechanical properties over the entire section of the rail. The disadvantages include the difficulty of ensuring the required tolerance for the length of the rails

The technology of anti-flake rail treatment with delayed cooling does not allow to carefully control and maintain the same cooling rate throughout the charge volume.

Technological scheme of thermal rail hardening with heating of tp. (high-frequency currents) guarantees high mechanical properties of the rolling surface of the head, allows to provide limited tolerances along the length of the rail. The disadvantages of this technology are the reduced impact toughness of the neck and sole due to the formation of the structure of coarse-lamellar pearlite during rolling, which can lead to the formation and development of fatigue cracks during operation, more often in the area of the fastening holes.

To increase the durability of rails, it is promising to use the following methods:

- improving the quality of carbon steels through the use of complex deoxidizers containing $\mathrm{Si}, \mathrm{Mn}, \mathrm{Al}$;

- use of steels with a high carbon content (up to $0.88 \%$ ) and microalloying by $\mathrm{Cr}, \mathrm{V}$;

- switching from ingot casting of rail steels to continuously cast billets will reduce the flock sensitivity and grind the original austenite grain to 8-9 points, which will increase the toughness of the rails. 


\section{References}

1. V. Albrecht, N. Vinogorov, N. Zverev and etc. Continuous path. Moscow (2000)

2. T. Yakovleva, N., Korpuschenko, S. Klinov and etc. Rail. tranck. Moscow, 407 p., (1999)

3. I.Kuchuk-Yatsenko, A. Didkovsky, V. Shvets, P. Rudenko, E. Antipin, Autom. Weld., 5-6 (753), pp. 7-16, (2016)

4. N. Kozyrev, R. Shevchenko, A. Usoltsev, Bull. "Black metal.”, 2 (2018)

5. A.Tokareva, Way and track ec. 4, pp. 121-141 (2002)

6. N.Voronin, O.Trynkova, O.Fomicheva, Alum.-ther. Weld. of rails in winter, Worl. of trans., 4 pp. 56-59 (2012)

7. V. Karguin, L.Tikhomirova, M.Galay, Weld. Intern., V.29 2, pp. 155-157 (2015)

8. Yu. Rukavchuk, S.Rozhdestvensky, I.Etingen, Path and track fac., 4, pp. 26-27 (2011)

9. Shur E.A. Infl. of met. Matr. Prop. on serv. Resis. of rails: Ss. Art., pp.37-63 (2006) 